\title{
Bronchial Asthma in Servicemen - A Personal View
}

\author{
Colonel J Carson \\ MB, ChB, FRCP, DTM \& H, L/RAMC \\ *Army Chest Centre, Cambridge Military Hospital, Aldershot, Hants. GU11 2AN
}

SUMMARY: This paper is a review of 59 serving male officers and soldiers with bronchial asthma who attended the Chest Clinic at the Cambridge Military Hospital during a defined period of time and who had been under the care of the author for periods of up to six years. The patterns of presentation, management, progress and outcome are described. Exercise induced asthma is seen as the biggest problem for servicemen often with otherwise mild asthma, and there is evidence that potential recruits are still not being adequately assessed. In younger men, exercise associated disability is an early symptom. but older individuals tend to divide into one group with early exercise related problems and another who remain able to exercise at least for a time. Response to prophylactic therapy is good, but it is often difficult to eliminate exercise induced wheeze in military training and relapse is common when prophylaxis is withdrawn. The effect of this on medical category is described and some of the implications are discussed.

\section{Introduction}

Bronchial asthma is a common condition underdiagnosed in childhood ${ }^{1}$ and probably in adults also. It is by definition variable and this variability extends to its natural history. The army physician and his patient seldom stay together long enough for the doctor to follow the course of the disease in an individual patient. The author had the opportunity to follow some patients at least for up to six years at the Army Chest Centre. This paper presents some observations on the disease in these officers and soldiers, referred to together as servicemen.

\section{Materials and Methods}

All trained servicemen who presented to the Army Chest Centre from November 1979 to February 1986, and were still attending in the period July 1985 to February 1986 inclusive, were studied. Recruits and soldiers who had not completed basic training have been studied previously ${ }^{2,3}$ and were not included in this series. Although the study is retrospective, the earlier study in assessing recruits had revealed the importance of detailed specific questioning for symptoms and these had been recorded together with ventilation test results at initial and subsequent attendance. Patients were usually seen every 2 to 3 months initially, extending to 6 months in stable patients, and the same general treatment policy was applied throughout. It was therefore possible to extract data on symptoms, exercise performance, ventilatory function and treatment at various times from presentation, as well as data about past history and assessment on entry. A score of 1 was attached to all but one of the recorded symptoms. Dyspnoea on "ordinary" running was given a score of 2 to distinguish it from exercise associated wheeze under other circumstances as will be described. This allowed a simple assessment of response to treatment to be made.

\section{Results}

The Patients. A total of 59 servicemen were studied of whom 27 were other ranks or junior NCOs, 19 were *Now: BMH Munster, BFPO 17 senior NCOs or warrant officers and 13 officers including 2 lieutenant colonels. During the period one corporal was promoted to sergeant and one lance corporal to WO2. Ages at presentation ranged from 18 to 48 years, the distribution being shown at Figure 1.

Past History and Assessment on Entry (Table 1) Twenty individuals, 11 of whom were aged 30 years of more, had no past history of respiratory disease, anothesp 11 had a past history of hayfever but denied any lowe respiratory symptoms before the onset of their present symptoms. Twenty eight had a history of wheezक dyspnoea under various circumstances in childhood, 10 of whom stated that this had never been diagnosed as asthma. Of the 16 with a known history of childhood asthma, only 2 had been assessed by an exercise test 8 previously recommended by this unit ${ }^{2}$. Nevertheless, had completed basic military training and many had given several years of service without problems, and had probably been in genuine remission ${ }^{3}$.

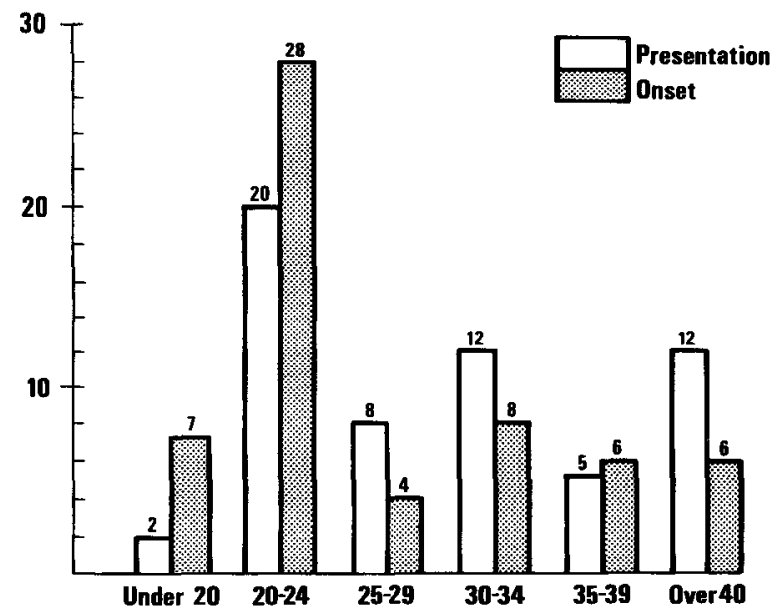

Fig 1. Servicemen with Asthma. Ages at presentation and at onset of symptoms. 
Table 1

Servicemen with asthma.

Past history (PH) \& Assessment on Entry

\begin{tabular}{llllllll}
\hline $\begin{array}{l}\text { Age at onset } \\
\text { (Years) }\end{array}$ & $<20$ & $20-24$ & $25-29$ & $30-34$ & $35-39$ & $>40$ & Totals \\
\hline
\end{tabular}

PH Asthma

Properly Assessed

PH Asthma

Not Assessed

PH Asthma

Not Recognised

2

7

1

1

1

PH Hayfever

Only

6

2

2

1

No Relevant PH
Presenting Symptoms (Figure 2). Wheezy dyspnoea sufficient to interfere with military training was the commonest symptom and reason for referral. "Ordinary"running means the level required in the basic fitness test (BFT), i.e. steady running for 10 to 15 minutes. "Vigorous" running implies sustained running over irregular ground, usually in combat clothing. The frequency of symptoms under the above circumstances is seen to be considerably greater than in conventional sport. Only 5 individuals had no exercise related wheeze and a further 5 had symptoms only in the hayfever season. All patients were asked about symptoms in a variety of circumstances. Nocturnal and early morning wheeze were common when specifically asked for, although seldom volunteered as symptoms. Two patients, however, had nocturnal wheeze as their only symptom.

Age at onset of significant dyspnoea. The age at which symptoms first occurred or relapsed is shown as the age at presentation in Figure 1. There was a noticeable variation between the time of onset of symptoms and the time before dyspnoea interfered with military training, i.e "significant" dyspnoea (Table 2). A very abrupt onset, often identifiable to the day, was seen in some younger individuals who, up to that time, had experienced no problems in training. Thirty one individuals $(53 \%)$ had a problem within one year of onset. At 5 years $45(76 \%)$ had a problem and at 6 years $49(83 \%)$ were affected. Servicemen whose asthma appeared at age 35 years or over appeared to fall into two distinct groups; one developed significant dyspnoea early, and the other remained apparently unaffected.

Basic Fitness Test (BFT) performance at presentation. All the patients were under 50 years of age and were required to perform this test twice yearly. Two men, however, were graded $\mathbf{P 7}$ for non-respiratory reasons

\begin{tabular}{|c|c|c|}
\hline Precipitant & Frequency & \\
\hline Ordinary Running * Anytime & & \\
\hline Respiratory Infection & & 27 \\
\hline Nocturnal & & 26 \\
\hline Early Morning & & 15 \\
\hline Vigorous Running & 9 & "t \\
\hline Ordinary Running - Hayfever Season & 6 & \\
\hline Hayfever & $\sqrt{5}$ & \\
\hline Domestic Pets & 4 & \\
\hline Nonspecific Irritants & 4 & \\
\hline Evenings & 3 & \\
\hline Ordinary Outdoor Sports & 3 & \\
\hline Unidentified Spontaneous & 3 & \\
\hline Constant of Near Constant & 8 & \\
\hline Cold Air & 1 & \\
\hline
\end{tabular}

* 15 minutes steady running as required for the Basic Fitness Test

Fig 2. Servicemen with Asthma. Precipitants noted at initial presentation.

and a 42 year old lieutenant colonel claimed he had never done the test! With these exceptions the BFT had been passed by all the individuals prior to the onset of symptoms. Table 3 shows BFT performance in relation to age at presentation and emphasises the earlier comment about dyspnoea in military training. Thirty six individuals had failed the test or had been unable to achieve the necessary standard in training and a further 3 had received bronchodilators in order to succeed. Nevertheless, 20 men had passed the test in the previous 6 months despite asthmatic symptoms.

Clinical Findings. Few patients had audible wheeze in the clinic, but all clinics were held in the afternoon when 0 air flow is likely to be optimal in asthmatics. Our 
Table 2

Servicemen with asthma.

Age at onset/and duration before the onset of significant dyspnoea

\begin{tabular}{lcccc}
\hline $\begin{array}{l}\text { Age at } \\
\text { onset } \\
\text { (years) }\end{array}$ & \multicolumn{5}{c}{ Years between onset \& occurrence of significant dyspnoea } \\
\hline$<20$ & $<1$ & $\mathbf{1 - 5}$ & $>\mathbf{5}$ & No significant dyspnoea \\
$20-24$ & 7 & & & 2 \\
$25-29$ & 13 & 12 & 2 & 1 \\
$30-34$ & 1 & 2 & 2 & 3 \\
$35-39$ & 4 & & 2 & 2 \\
$>40$ & 2 & & & $\mathbf{1 0}$ \\
\hline Totals & 4 & & $\mathbf{4}$ & 2 \\
\hline
\end{tabular}

Table 3

Servicemen with asthma.

Performance on BFT at presentation

\begin{tabular}{|c|c|c|c|c|c|c|c|}
\hline Not Attempted & 2 & 7 & 2 & 2 & 2 & 6 & 21 \\
\hline Failed & & 4 & 3 & 5 & 1 & 2 & 15 \\
\hline Passed on Treatment & & 1 & 1 & & & 1 & 3 \\
\hline Passed. No Treatment & 1 & 8 & 2 & 5 & 2 & 2 & 20 \\
\hline
\end{tabular}

\begin{tabular}{lllllllll}
\hline Age Group (Years) & Under 20 & $20-24$ & $25-29$ & $30-34$ & $35-39$ & Over 40 & Total
\end{tabular}

observations on healthy servicemen, including smokers, suggest that the forced expiratory volume in 1 second (FEVI) and the forced vital capacity (FVC) are generally higher than those in standard tables and the normal forced expiratory ratio (FER) is about $80 \%$. Table 4 shows the distribution of FER in these patients. Sixteen had an FER in the conventional normal range of $75 \%$ or more. The average FER in these was $114 \%$ of predicted normal (range $98.2 \%$ to $132.3 \%$ ). Exercise lability tests were done on 6 of them and the mean lability index was 38.7 (range 28 to 56.5). A further individual had a diurnal variation in air flow of $90 \%$. The average FER in the 43 individuals with a result of $60 \%$ or more was still $99 \%$ of predicted normal. Fifteen of these had a mean exercise lability index (ELI) of 34.8 (range 8.2 to 87.8 ). The only man with a normal ELI subsequently worsened and had an abnormal result one year later. A definitely abnormal resting ventilatory pattern was uncommon in younger men but present in half of those over age 40 .
Treatment. The general policy adopted with newly referred patients was to treat them vigorously with prophylactic inhalations in the hope of inducing a remission. This consisted of inhaled sodium cromoglygate Intal, 2 puffs 4 times daily and before exercise, and some patients also received beclomethasone as Becotide, 2 puffs 4 times daily, but more recently, as Becloforte, 2 puffs twice daily. Patients were instructed to use a salbutamol inhaler Ventolin promptly if they wheezed and to use this before exercise on occasion. The use of inhalers was demonstrated to patients in all cases. They were encouraged to take exercise on the understanding that they stopped and used salbutamol promptly if they developed unpleasant wheeze. Patients with troublesome nocturnal wheeze were given long acting salbutamol Ventolin spandets at night and told to stop this therapy at weekly intervals to see if the symptom had gone. Once remission was achieved, prophylaxis was progressively reduced and stopped if possible. 
Table 4

Servicemen with asthma.

Forced expiratory ratio at presentation

\begin{tabular}{lccccccc}
\hline $75 \%$ or More & 1 & 6 & 3 & 4 & 1 & 1 & 16 \\
$70-74.9 \%$ & 1 & 5 & 1 & 3 & & 3 & 13 \\
$60-69.9 \%$ & & 6 & 2 & 2 & 2 & 2 & 14 \\
$59.9 \%$ or Less & & 3 & 2 & 3 & 2 & 6 & 16 \\
& & & & & & & \\
\hline Age Group & Under 20 & $\mathbf{2 0 - 2 4}$ & $\mathbf{2 5 - 2 9}$ & $\mathbf{3 0 - 3 4}$ & $\mathbf{3 5 - 3 9}$ & Over 40 & Total \\
\hline
\end{tabular}

Twenty five individuals received Intal and beclomethasone and 15 Intal alone as initial prophylaxis. The remainder had special features such as seasonal asthma or a reluctance to have to "depend" on treatment. Subsequently 8 of the latter received at least Intal as a prophylactic because of persistent or increasing symptoms.

Outcome. Table 5 provides an overall picture of the effect of treatment on symptoms. Forty seven men had attended for a year or more and had a mean initial symptom score of 3.23 compared to 3.14 symptoms in the whole group. The mean symptom score fell to 1.09 in patients reviewed at one year, the majority of whom were on prophylaxis. Only 15 individuals on prophylactic treatment became either symptom free or had only trivial symptoms not interfering with military training (symptom score 0.67 ) and most had more symptoms when prophylaxis ceased (score 1.40). Those 7 who were totally symptom free on prophylaxis did only marginally better (score 1.28) than the rest of this subgroup. Unfortunately, relapse follows withdrawal of prophylaxis. The following case summary illustrates the problem:

Private A.B. Aged 20. No relevant past history. Sudden onset of exercise induced asthma 6 months earlier. FEVI 5.4L, FER 80.1\%. ELI 40. Treatment Intal + Ventolin. At 3 months completely symptom free. Prophylaxis phased out. At 12 months-recent nocturnal and early morning wheeze, exercise wheeze and had failed BFT. Graded P3 LE. Intal and Becloforte commenced. At 2 years - tried to discontinue prophylaxis, but had exercise induced wheeze and failed BFT. Graded P6 BT. FEVI 3.65L, FER 66\%, ELI 51 . Intal and Becloforte continued. At 3 years - only symptom was wheeze when doing BFT training. FEVI $4.92 L, F E R \quad 81.3 \%$. Able to complete course but outside time limit. Remains P6 BT.

While this story is typical of the majority, and particularly that of younger servicemen, some individuals appeared less significantly affected and were still P2 at one year after presentation (Table 6).

Five men were unusually fit even by the most desirable military standards and denied any exercise induced wheeze initially. One was an SAS NCO whose only symptom was nocturnal wheeze. Resting ventilation was normal but his ELI was 34.9. He also had isolated house dust mite sensitivity on prick testing and is one of ver few patients receiving immunotherapy. Meanwhile? contrary to the received view, his symptom is controlled

Table 5

Servicemen with asthma. Symptom scores in relation to treatment

\begin{tabular}{ccc} 
Symptom & Score/Number \\
Group & Mean Score \\
\hline
\end{tabular}

All Servicemen

Initial Scores

$182 / 58^{*}$

3.14

All Reviewed Over One Year Initial Scores

$152 / 47$

All Reviewed Over One Year Scores on Prophylaxis

$51 / 47$

1.09

All Reviewed Over One Year Able to Stop Prophylaxis

$10 / 15$

Scores on Prophylaxis

All Reviewed Over One Year Able to Stop Prophylaxis $21 / 15$ 1.40

Scores After Stopping

Those Who Became Totally Symptom Free on Prophylaxis Scores After Stopping

*Excluding one patient who "wheezed all the time except when running"! 
Table 6

Servicemen with asthma.

Characteristics of those still P2 FE one year after presentation

\begin{tabular}{|c|c|c|c|c|}
\hline & & Mean & m score & \\
\hline Group & NUMBER & Initial & One Year & COMMENTS \\
\hline $\begin{array}{l}\text { No exercise dyspnoea } \\
\text { at presentation }\end{array}$ & 5 & 1.75 & 1.75 & $\begin{array}{l}1 \text { NCO in SAS. } \\
\text { Nocturnal wheeze only. ISQ at } 2 \text { yrs controlled by Intal. } \\
2 \text { officers Parachute Regt. One later required EIA } \\
\text { treatment. } 2 \text { habitual marathon runners both later } \\
\text { required EIA treatment. }\end{array}$ \\
\hline $\begin{array}{l}\text { Mild symptoms only in } \\
\text { pollen season }\end{array}$ & 5 & $2.4^{*}$ & 0 & $\begin{array}{l}3 \text { remained in remission next year. } 1 \text { had "Intal" } \\
\text { prophylaxis next year. } 1 \text { deteriorated later. }\end{array}$ \\
\hline $\begin{array}{l}\text { Complete remission on } \\
\text { stopping therapy }\end{array}$ & 5 & 3.8 & 0 & $\begin{array}{l}1 \mathrm{Lt} \text { Col of } 43 \text { who never runs. } 2 \text { relapsed later. } \\
2 \text { remission of } 3 \text { to } 6 \text { months to date. }\end{array}$ \\
\hline $\begin{array}{l}\text { Trivial symptoms on } \\
\text { stopping therapy }\end{array}$ & 1 & 4 & 1 & $\begin{array}{l}\text { Occasional early morning } \\
\text { wheeze. }\end{array}$ \\
\hline Still on prophylaxis & 1 & 4 & 1 & Minor wheeze on exertion. Activity not restricted. \\
\hline
\end{tabular}

*Mainly (6) from 1 case

+EIA - exercise induced asthma.

by Intal at bed time. The other 4 all had definitely abnormal resting ventilation. Only one was given an exercise test and his ELI was 30.4. Three of these 4 required treatment for exercise induced asthma during the second year after presentation.

Six men reported wheeze only in the hayfever season. One of these was very wheezy initially (FER $51.1 \%$ ) and was still abnormal in the autumn despite prophylaxis (FER 68.9\% ELI 30) although he stated he was symptom free; he is, however, downgraded. Five other men with the same presentation fared better at one year when 4 were well, although one required Intal briefly in the second summer. One of the 4 , however, deteriorated in the second year. Six individuals appeared to be in remission for periods of 3 to 6 months when reviewed one year after presentation, but on follow up remission was usually not maintained. The lieutenant colonel who had avoided BFT (and other exercise) was a lifelong asthmatic with a symptom score of 3 (probably 5 if he had tried to run) and an initial FER of $48 \%$ rising to normal $(86.5 \%)$ on Intal and Becotide. He reported complete well being at 6 and 12 months when he was posted elsewhere. Of the other 4 in complete remission, 2 had relapsed and 2 had remained in remission for periods ranging from 3 to 6 months.

The outcome with respect to PULHHEEMS employment standard (PES) is shown at Table 7. Two men with long service were already $\mathrm{P} 7$ when seen and one has now completed his service. The remainder were originally $\mathrm{P} 2 \mathrm{FE}$. The 3 men invalided $\mathrm{P} 8$ were a 20 year old private who did not respond to prophylaxis, an 18

year old who relapsed immediately prophylaxis was? reduced and a 22 year old who relapsed after one year in remission. A fourth 22 year old who was $\mathrm{P} 3 \mathrm{LE}$ at the time of the survey was invalided in April 1986 when heo relapsed again after a second trial of prophylaxis. Of the 20 men who were P2 FE at one year, 3 have left theo Army on completion of service and the characteristics of the remainder have already been described (Table 6)

Table 7

Servicemen with asthma. Pulheems employment standard (PES)

\begin{tabular}{ccc}
\hline PES & $\begin{array}{c}\text { At One Year } \\
\text { or Later }\end{array}$ & Discharged \\
(P8 or Completion of Engagement)
\end{tabular}

\begin{tabular}{lll}
\hline P8 & 3 & 3 \\
P7 HO & 3 & 1 \\
P6 BT & 4 & \\
P3 BE & 1 & \\
P3 LE & $9^{*}$ & 1 \\
P2 FE & 20 & 3 \\
\hline
\end{tabular}

*One relapsed and boarded $P 8$ shortly after original review period. 
Of those continuing to attend, one is still on a trial of treatment and his PES will be assessed on the outcome with downgrading if remission is not complete. Six others have relapsed and are currently on a second trial of prophylaxis with the implication that failure to respond or further relapse will lead to downgrading.

Table 8 shows the status of 14 men who have been followed for between 3 and 6 years. One man was invalided in the third year and three others left the Army on completion of service. Four remain P2 FE and 3 of these had pollen associated asthma. One of these latter has recently developed more marked asthmatic symptoms which are likely to affect his PES. The fourth is a fit officer in the Parachute Regiment who, after 2 years, developed exertional wheeze and is now on a trial of treatment. His PES too is in doubt.

\section{Discussion}

It must be emphasised that this paper describes a sample of asthmatic servicemen who were attending the Army Chest Centre. It is therefore likely that bias is present because of accidents of posting, the exclusion of individuals invalided before the period of the sample and the possibility that medical downgrading may have

Table 8

Servicemen with asthma.

Status after 3 to 6 years of follow up

\begin{tabular}{|c|c|c|c|c|c|c|}
\hline $\begin{array}{l}\text { Years } \\
\text { of } \\
\text { Review }\end{array}$ & $\begin{array}{c}\text { Present } \\
\text { Age }\end{array}$ & PES & On Prophylaxis & Comment & $\begin{array}{l}\text { Current } \\
\text { Symptom } \\
\text { Score }\end{array}$ & 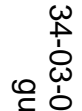 \\
\hline 3 & 26 & P8 & Yes & Repeated relapse & 4 & \\
\hline 3 & 24 & P3 LE & Yes & Stable on treatment & 0 & \\
\hline 3 & 23 & P6 BT & Yes & Stable-minor symptoms & 3 & 这 윰 \\
\hline 3 & 29 & P2 FE & Pollen Season only & Intal in summer only & 0 & $\underset{0}{\overrightarrow{0}}$ \\
\hline 3 & 30 & P2 FE & Yes & Recent relapse on trial of Intal & 0 & \\
\hline 3 & 34 & P7 HO & Yes & Considerable wheeze & 6 & $\stackrel{\substack{0\\
}}{P}$ \\
\hline 3 & 43 & P2 FE & Yes & $\begin{array}{l}\text { Was seasonal only. Recent } \\
\text { increase in symptoms \& } \\
\text { duration }\end{array}$ & 1 & $\frac{0}{\stackrel{2}{ి}}$ \\
\hline 3 & 23 & P6 BT & Yes & $\begin{array}{l}\text { Brittle. Relapses if prophylaxis } \\
\text { stopped }\end{array}$ & 2 & \\
\hline 3 & 24 & P2 FE & $\begin{array}{l}\text { Pollen season only } \\
\text { but not 3rd year }\end{array}$ & Treated by Vaccine & 0 & \\
\hline $5^{*}$ & 39 & P3 LE & No & $\begin{array}{l}\text { Uses Ventolin for exercise. } \\
\text { Marathon runner. }\end{array}$ & 2 & \\
\hline $5^{*}$ & 37 & P3 BE & Yes & $\begin{array}{l}\text { Bandsman. Repeated relapses } \\
\text { if treatment stopped }\end{array}$ & 0 & \\
\hline $6^{*}$ & 39 & P3 LE & Yes & Relapses if treatment stopped & 2 & 3 \\
\hline 6 & 54 & P3 BE & Yes & $\begin{array}{l}\text { Relapses if treatment stopped. } \\
\text { Chronic wheeze }\end{array}$ & 4 & \\
\hline 6 & 37 & P3 LE & No & Cannot pass BFT. Also obese. & 2 & \\
\hline
\end{tabular}


concentrated patients in this area. Nevertheless, the observations are fully in accord with the impression gained about servicemen with asthma over many years and may be used to emphasise certain points.

It is generally accepted that asthma is underdiagnosed in childhood ${ }^{1}$ and it has been previously demonstrated that mild but significant symptoms were overlooked at pre-service medical examination ${ }^{2}$. This in turn led to recruits with asthma being accepted but failing during initial training, a situation which has improved considerably at least in this area since our survey of recruits and potential recruits in 1980-81. This survey confirms that about one third of the younger subjects probably had undiagnosed childhood asthma and that only 2 of 13 young subjects with a known history of asthma had been assessed in the way which had been previously recommended. The group reported on here were of course selected from those who had succesfully completed basic training and would probably have passed an exercise test on entry ${ }^{3}$. The observations suggest however, as the author knows is in fact the case, that recruits are still being accepted without adequate assessment.

When relapse occurs it is most commonly in those under 25 years of age. The exclusion of recruits in training from this survey may well have reduced the potential numbers in the 18 to 19 age group. Nevertheless, in trained soldiers, relapse occurred most commonly at age 20 (8 cases) and, as it happens, there were 5 cases in each year of the age range 21 to 25 years. These relapses, or occasionally apparent first attacks of asthma, often occur abruptly at this age and result in impaired physical performance within a year of onset in the majority and in almost all cases within 5 years. This is reflected in the referral pattern where most cases either failed BFT or could not manage BFT training. This failure is commonly in the second part of the test the best effort run - and it is known that 6 to 8 minutes steady running is optimal for inducing wheeze ${ }^{4}$.

Patients developing symptoms after the age of $30 \mathrm{can}$ be divided into two groups, one of which behaves like the younger subjects and a second group who manage well, with some initially maintaining a high standard of physical performance despite a tendency to a worse resting ventilatory pattern.

Most patients have at least one other symptom apart from exercise induced wheeze in military training, although it is notable that wheezing with sport was uncommon, perhaps because short spurts of activity are protective $^{5}$.The survey suggests that when specifically asked, a large number will have nocturnal and early morning wheeze although these are seldom volunteered as symptoms.

Many of these patients have a very mild asthma by civilian standards and prebably would not attend a clinic or even be seen by their doctor were it not for the exercise related problem. Mild airflow obstruction is not audible with the stethoscope, but in any case most cases had normal resting ventilation despite the generally abnormal lability recorded in those tested. The doctor first seeing these patients, therefore, must not allow his suspicions to be allayed by normal findings in his clinic, and should be aware that in fit men the absolute values of FEV1 and FVC should be above the "normal". Once the diagnosis is made, a distinction is drawn between treating the bronchospasm with a beta-agonist, and treating the underlying bronchial hyper-reactivity with an appropriate prophylactic as already described.

A good remission can usually be obtained, which is not surprising given the relatively mild asthma of most $\bar{c}$ cases. It is however difficult to eliminate exercise $\vec{\nabla}$ induced asthma in the context of military training and even when this is achieved relapse is common, usually within 6 to 12 months after prophylaxis is withdrawn. $\overrightarrow{0}$ Asthma occurring only in the pollen season appears initially to be less troublesome, but recurs and may well $\vec{\omega}$ appear outside the season with the passage of time. Those individuals in the older age group who can continue military training manage well in the short term and some can cope with very vigorous activity despite $\vec{\omega}$ undoubted asthma, a phenomenon recorded in sportsmen $^{6}$. As the period of follow up lengthens however, many of these too come to need prophylact treatment.

The apparently encouraging outlook foo? PULHHEEMS Employment Standard (PES) at on $\overrightarrow{\mathrm{Q}}$ year is, therefore, false. It reflects in part the author habit - which may be criticised as too generous - of no downgrading most soldiers until they either fail a trial of treatment or relapse following a trial. When follow un for 3 or more years was achieved, all the patients hag relapsed to a greater or lesser degree, and at least 2 , not all 3 , of those remaining $\mathrm{P} 2$ were at risk downgrading.

This survey has reinforced the impression that young asthmatic servicemen quickly develop a problem with $\stackrel{\mathbb{D}}{\mathbb{D}}$ exercise and repeated relapses then occur despite the often excellent control with prophylactics. Older individuals behave similarly or have a generally slower deterioration, but most come to need prophylaxis within 5 years. It is felt that, in the long term, the serviceman should only remain $\mathbf{P} 2$ if he can perform normal duty without needing regular prophylaxis. Those who can do normal training with prophylaxis are graded P3 LE. Where asthma is difficult to control the PES should probably be no higher than $\mathrm{P} 3 \mathrm{BE}$ or $\mathrm{P} 6 \mathrm{BT}$. In younger men in particular, the interests of the man and of the service may be better served by invaliding.

\section{Acknowledgement}

The author would like to thank the Department of $\frac{T}{O}$ Physiological Measurements for the many function tests they performed and also Helene Blythe for typing this of manuscript and many pages of notes. 


\section{REFERENCES}

1. SPEIGHT A N P. Is childhood asthma under diagnosed and under-treated? Br Med J 1983; 286: 1253-5.

2. CARSON J and Winfield C R. Exercise testing in Servicemen with asthma and its application to the assessment of potential recruits. J Army Med Corps 1983; 129: $14-18$.

3. WiNFIELD C R and CARSON J. Exercise induced asthma in young male asthmatics with symptoms and in remission.
J R Army Med Corps 1985; 131: 21-23.

4. ANDERSON S D, et al. Exercise induced asthma. Br J Dis Chest 1975; 69: 1-39.

5. Schnall R P and Landau L I. Protective effect of repeated short spurts in exercise induced asthma. Thorax $\mathbb{D}$ $1980 ; 35: 828-832$.

6. Clinical Curio. Does aggressive sport protect against exercise induced asthma? $\mathrm{Br}$ Med J 1985; 291 : 1106.

\section{HONORARY APPOINTMENTS}

Lieutenant Colonel C A Gauci, RAMC has been appointed Honorary Consultant in Pain Relief at Guy's Hospital.

Major M A Staunton, RAMC has been appointed Honorary Lecturer in the Department of General Practice in the Medical College of St. Bartholomew's Hospital. 